\title{
A paper platform for colorimetric determination of aluminum hydrochloride in antiperspirant samples
}

\author{
Amanda Letícia Polli Silvestre, Maria Izabel Milani, Eduardo Luiz Rossini, \\ Leonardo Pezza, Helena Redigolo Pezza*
}

Instituto de Química, Universidade Estadual Paulista “Julio de Mesquita Filho", UNESP, R. Prof. Francisco Degni 55, P.0. Box 355, 14800-900 Araraquara, SP, Brazil

\section{A R T I C L E I N F O}

\section{Article history:}

Received 28 March 2018

Received in revised form 11 June 2018

Accepted 13 June 2018

Available online 15 June 2018

\section{Keywords:}

Diffuse reflectance

Aluminum

Paper platform

Antiperspirant

\begin{abstract}
A B S T R A C T
A simple, fast, low-cost, portable, and eco-friendly method using a spot test on a paper platform, together with diffuse reflectance spectroscopy, was developed and validated for the quantification of aluminum hydrochloride, a potential neurotoxic agent, in antiperspirant samples. The determination of aluminum hydrochloride was performed at a wavelength of $615 \mathrm{~nm}$, by measuring consumption of the purple colorimetric reagent Alizarin S, due to reaction with aluminum. The linear range was from 10.0 to $125.0 \mathrm{mg} \mathrm{L}^{-1}$ and could be described by the equation: $A_{R}=0.4479-0.002543 C_{\mathrm{Al}}(R=0.999)$. The limits of detection (LOD) and quantification (LOQ) were 3.06 and $10.2 \mathrm{mg} \mathrm{L}^{-1}$, respectively. The method was specific, accurate, and repeatable, with relative standard deviation (RSD) $<5.0 \%$. The recovery was between 92.2 and $103.4 \%$. The method was successfully used for the determination of aluminum hydrochloride in commercial antiperspirant samples, revealing concentrations below the maximum permitted by current legislation.
\end{abstract}

(c) 2018 Elsevier B.V. All rights reserved.

\section{Introduction}

Personal hygiene has become a part of the daily routine worldwide, reflecting the concern of individuals about their welfare. Personal hygiene products such as antiperspirants and deodorants are considered indispensable, because they are no longer merely a way to maintain a sensation of cleanliness, but also contain components that treat and beautify the skin, such as vitamin $\mathrm{E}[1,2]$.

Perspiration is a fundamental physiological process whose function is to control and maintain the body temperature at around $37^{\circ} \mathrm{C}[3]$. There are three different ways to reduce or control underarm odor: minimization or elimination of the secretions from both types of sweat glands; prevention of bacterial growth; and absorption of body odors. For these purposes, two different product categories are available, namely deodorants and antiperspirants [2]. Deodorants only control odor, while antiperspirants are formulated to reduce local perspiration and usually also contain components to combat bad odor. Different to deodorants, antiperspirants reduce the amount of sweat produced locally by the human body and are therefore considered drugs, since they alter the normal physiology of the body [1].

Aluminum and its derivates have a broad range of applications in many different fields, including in the cosmetics and pharmaceutical industries [4]. Many of the antiperspirant products currently used contain aluminum compounds as the active agents [5-7].

\footnotetext{
* Corresponding author.

E-mail address: hr.pezza@unesp.br (H.R. Pezza).
}

Aluminum hydrochloride (AHC) is the main active compound in antiperspirants. Its mechanism of action consists of the precipitation of $\mathrm{AHC}$ in the interior of the sweat glands, producing insoluble aluminum hydroxide that binds in the gland and blocks sweat secretion $[1,8]$. Some antiperspirants, especially metal salt solutions, also exhibit bactericidal action and deodorant effects [7]. The skin is the main route for entry of aluminum contained in antiperspirant products, and this transdermal absorption can lead to aluminum overload, which may result in anemia, bone disease, or even dementia, notably in individuals with poor renal function [9]. The metal is potentially neurotoxic [10], so its accumulation can cause diseases such as Parkinson's, Alzheimer's, encephalopathy, and osteomalacia [11, 12]. Furthermore, the daily use of antiperspirants can irritate the skin, causing rashes and burning sensations, while more severe skin irritation can lead to desquamation or even necrosis [13].

In order to regulate the sale and use of this type of product, it is fundamental to ensure adequate supervision by governmental agencies. In Brazil, the entity responsible is the National Health Surveillance Agency (ANVISA), which stipulates a maximum of $25 \%$ of aluminum salts in the composition of antiperspirants and deodorants [14]. In Brazil, these products are classified as risk grade 2 , with potential danger to health [15-17].

There are several methods that can be used to determine aluminum in antiperspirant samples, including pre-column derivatization and HPLC-UV/Vis detection [18], flow injection analysis with spectrophotometric detection [19], and atomic absorption spectroscopy [20], among others. Most of these methods require the use of organic solvents or 


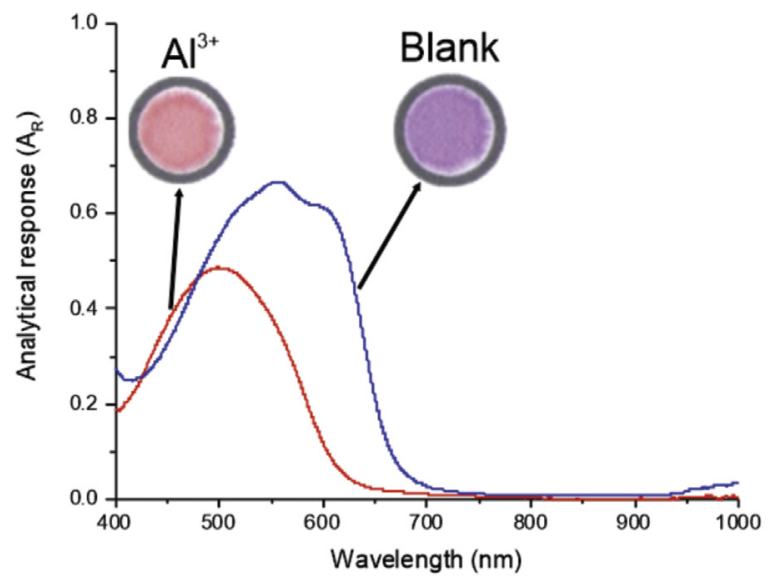

Fig. 1. Diffuse reflectance spectra of Alizarin S in alkaline medium (blue line) and the AlAlizarin S complex (red line). Examples of spot tests for the blank and an aluminum solution.

derivatization steps, which may cause harm to the operator and the environment. Additional considerations are that the analyses can be very expensive and require specialized operators.

An alternative to these methods is to use a spot test together with diffuse reflectance spectroscopy, which is a simpler, faster, and less expensive way to determine an analyte. In this type of analysis, aliquots of the reagent and sample are placed on a solid support, with quantification by measurement of a change in the analyte, such as a color alteration or even gas evolution [21]. Paper provides a good solid platform for diffuse reflectance measurements, due its high contrast and bright white background [22]. Paper platforms can be obtained from renewable sources and require the use of minimal volumes of reagent and sample, generating a negligible waste that is easily incinerated [23]. In order to improve the analytical response and color uniformity, the paper platforms used for spot tests can be impregnated with wax, creating hydrophobic barriers so that the solutions applied are restricted to the delimited area [24]. Several studies have described low cost and portable methodologies that use hydrophobic barriers in paper [25-27].

The present work describes a method for the determination of aluminum in antiperspirant samples, using a colorimetric reaction in a spot test delimited with hydrophobic barriers in a paper platform. The reddish reaction product was measured using diffuse reflectance spectroscopy. This method is fast, cheap, eco-friendly, and very simple to use.

\section{Materials and Methods}

\subsection{Materials and Solutions}

All reagents used were analytical grade. Aluminum nitrate nonahydrate and Alizarin S were purchased from Vetec. Sodium hydroxide was purchased from Sigma-Aldrich. Solutions and dilutions employed deionized water (18.2 $\mathrm{M} \Omega \mathrm{cm}$ ) obtained from a Milli-Q system (Millipore). A $0.1 \%(\mathrm{~m} / \mathrm{m})$ solution of Alizarin $S$ in deionized water was employed for the aluminum determination. A stock solution of $1000 \mathrm{mg} \mathrm{L}^{-1}$ of aluminum was prepared in deionized water. Working solutions of aluminum were freshly prepared by appropriate dilution of the stock solution in $1.00 \mathrm{~mol} \mathrm{~L}^{-1} \mathrm{NaOH}$.

\subsection{Sample Preparation}

Seven different samples of antiperspirant were purchased locally in the city of Araraquara (São Paulo State, Brazil). A mass of $0.125 \mathrm{~g}$ of each sample was transferred to a beaker, followed by addition of $25 \mathrm{~mL}$ of $2.00 \mathrm{~mol} \mathrm{~L}^{-1} \mathrm{NaOH}$ solution. The mixture was heated at ebullition for $5 \mathrm{~min}$, under constant stirring. After cooling, the content was filtered using a quantitative paper. The beaker and the filter were washed with $50 \mathrm{~mL}$ of $1.00 \mathrm{~mol} \mathrm{~L}^{-1} \mathrm{NaOH}$ solution, collecting the washings in a $100 \mathrm{~mL}$ volumetric flask that was completed to the meniscus with deionized water.

\subsection{Preparation of the Paper Platform}

Hydrophobic wax barriers ( $15 \mathrm{~mm}$ diameter, $0.75 \mathrm{~mm}$ thickness) were designed as described by Milani and co-workers [28], using graphical software (CorelDRAW X5). The printing was performed onto Whatman No. 1 filter paper, using a wax printer (Xerox Phaser 8560) and wax toner (Genuine Xerox Solid Ink Black), as described by Carrilho and co-workers [24]. The paper was heated for $120 \mathrm{~s}$ at $120^{\circ} \mathrm{C}$ for formation of the hydrophobic barriers.

\section{Methodology}

In the spot test, a $15 \mu \mathrm{L}$ aliquot of aluminum working solution or sample was applied to the center of the delimited area. After drying at room temperature, $15 \mu \mathrm{L}$ of Alizarin S solution was added, followed by further drying for about $10 \mathrm{~min}$. Diffuse reflectance measurements were performed using a portable spectrophotometer (USB2000, Ocean Optics) operated with OOIBase32 software (Ocean Optics).

\subsection{Study of Matrix Interferences}

Matrix interferences were evaluated using recovery tests. The sample matrix was fortified with standard solutions at levels from $50 \%$ to $200 \%$, followed by diffuse reflectance spectroscopy measurements.

\section{Results and Discussion}

\subsection{Preliminary Tests}

The Alizarin S chromogenic reagent was selected for the colorimetric determination of aluminum in antiperspirant. In an alkaline medium, the reagent has a purple color, while reaction with $\mathrm{Al}^{3+}$ (Fig. 1) results in the formation of a red complex (Fig. 2) [29-31]. A strongly alkaline<smiles></smiles>

Fig. 2. Reaction between Alizarin S and aluminum in alkaline medium. 


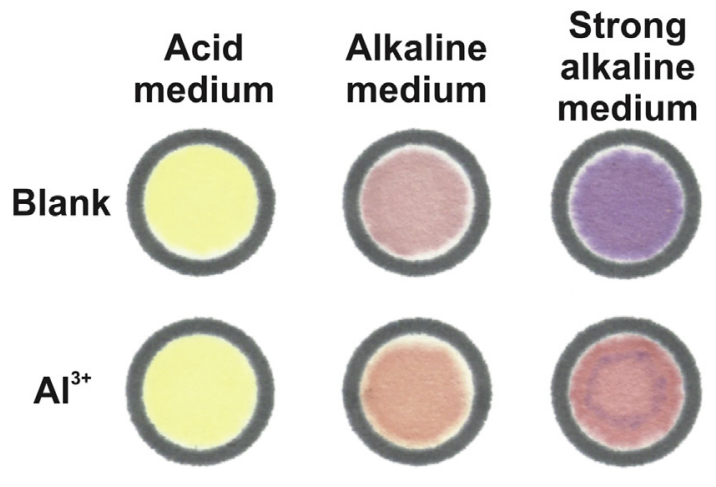

Fig. 3. Influence of $\mathrm{pH}$ on the reaction between aluminum and Alizarin $\mathrm{S}$, and on the development of color.

medium ( $\mathrm{NaOH}$ at $1 \mathrm{~mol} \mathrm{~L}^{-1}$ ) was selected for use in the development of the method, due to the color difference in the presence and in the absence of aluminum (Fig. 3), which enabled the quantification of aluminum by diffuse reflectance spectroscopy. In an acid medium ( $\mathrm{pH} 4$ ), there was no development of a different color in the presence of AHC. In a neutral medium, a gelatinous precipitate of $\mathrm{Al}(\mathrm{OH})_{3}$ was formed, while in an alkaline medium ( $\mathrm{pH}$ 9), there was a modest color difference in the presence of aluminum, compared to the blank. Furthermore, the samples were prepared in $1 \mathrm{~mol} \mathrm{~L}^{-1} \mathrm{NaOH}$ medium, eliminating a $\mathrm{pH}$ adjustment step for AHC determination, and due to the error in $\mathrm{pH}$ measurements under alkaline conditions, with a decrease in the $\mathrm{pH}$ value in the presence of high concentrations of $\mathrm{Na}^{+}$, it is preferable to work with $\mathrm{OH}^{-}$concentrations, rather than the $\mathrm{pH}$ scale.

Absorption by the reagent and the analyte occurs in the same wavelength range, but the reagent absorption presents a bathochromic shift. Therefore, the quantification of aluminum was achieved by measurement at $615 \mathrm{~nm}$ of the consumption of the purple reagent, avoiding spectral interference between the product and the reagent.

The best analytical response was achieved by first adding the aliquot of the sample or aluminum standard solution, followed by addition of the reagent solution. The use of the hydrophobic barriers provided a more homogeneous and intense coloration, decreasing the standard deviation and improving the analytical performance. The colored product was stable for at least $70 \mathrm{~min}$ after the reaction.

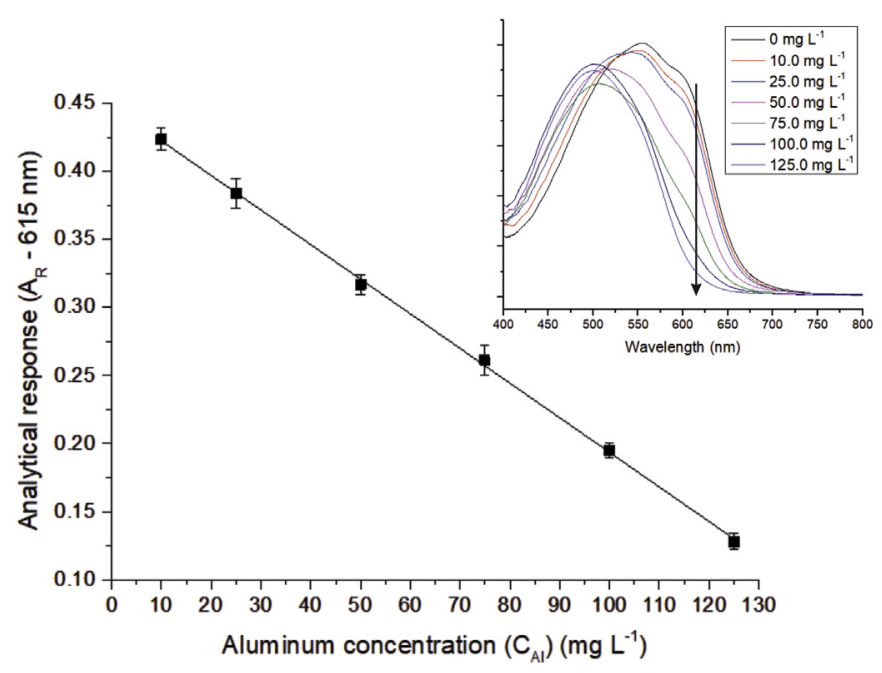

Fig. 4. Analytical curve for analytical response $\left(A_{R}\right)$ vs. aluminum concentration, and the change of the absorption spectra with increase of the aluminum concentration.
Table 1

Figures of merit of the proposed method.

\begin{tabular}{ll}
\hline Parameter & Value \\
\hline Linear range & $10.0-125.0 \mathrm{mg} \mathrm{L}^{-1}$ \\
Wavelength & $615 \mathrm{~nm}$ \\
Calibration curve & $\mathrm{A}_{\mathrm{R}}=0.4479-0.002543 \mathrm{C}_{\mathrm{Al}}$ \\
Coefficient of correlation (R) & 0.999 \\
LOD & $3.06 \mathrm{mg} \mathrm{L}^{-1}$ \\
LOQ & $10.2 \mathrm{mg} \mathrm{L}^{-1}$ \\
\hline
\end{tabular}

\subsection{Figures of Merit}

An analytical curve was constructed using the aluminum working standard solutions at concentrations from 10 to $125 \mathrm{mg} \mathrm{L}^{-1}$. A linear relationship was found between the analytical response $\left(A_{R}\right.$, at $\left.615 \mathrm{~nm}\right)$ and the aluminum concentration $\left(\mathrm{C}_{\mathrm{Al}}\right)$, described by $\mathrm{A}_{\mathrm{R}}=0.4479-$ $0.002543 C_{\mathrm{Al}}$ (Fig. 4), with $\mathrm{R}=0.999$ indicating good linear correlation.

The repeatability of the proposed method was evaluated using intraday and inter-day relative standard deviations (\%RSD), at two concentrations. For a $25 \mathrm{mg} \mathrm{L}^{-1}$ aluminum solution, the \%RSD values were $2.7 \%$ (intra-day) and 3.0\% (inter-day). The corresponding values for a $50 \mathrm{mg} \mathrm{L}^{-1}$ solution were $1.3 \%$ and $1.9 \%$, respectively. These results showed that the new method was repeatable and could be used for the determination of aluminum in antiperspirant samples.

The limits of detection (LOD) and quantification (LOQ) were calculated according to the IUPAC recommendations [32], using the following expressions: $\mathrm{LOD}=3 * \sigma / \mathrm{S}$ and $\mathrm{LOQ}=10 * \sigma / \mathrm{S}$, where $\sigma$ is the standard deviation of measurements of the blank $(n=10)$ and $S$ is the slope of the linear range. The values obtained were $3.06 \mathrm{mg} \mathrm{L}^{-1}$ (LOD) and $10.2 \mathrm{mg} \mathrm{L}^{-1}$ (LOQ). The technique was sufficiently sensitive to be able to determine aluminum in antiperspirant samples. Table 1 presents the figures of merits of the proposed method.

\subsection{Sample Analysis}

The method developed was used to determine the concentrations of AHC in seven different antiperspirant samples (Table 2). In addition to the quantitative analysis, a semi-quantitative visual determination could be performed by comparison of the colors obtained with a color palette (Fig. 5), which would be useful in situations where no diffuse reflectance spectrometer is available.

All the samples analyzed presented aluminum hydrochloride concentrations below the limit established by legislation [14], indicating compliance of the cosmetics industries with product quality criteria intended to protect the population, with no cases of excessive quantities of aluminum that might lead to health problems in consumers.

\subsection{Study of Matrix Interferences}

Antiperspirants contain various other substances besides aluminum hydrochloride, such as alcohols, EDTA, glycerin, paraffin, oil, and perfume. The presence of these substances could lead to increases or

Table 2

Quantification of AHC in commercial samples using the proposed method.

\begin{tabular}{ll}
\hline Sample & AHC concentration ${ }^{\mathrm{a}}(\%)$ \\
\hline A & $23.0 \pm 1.8$ \\
B & $19.9 \pm 0.9$ \\
C & $15.6 \pm 0.3$ \\
D & $20.2 \pm 0.6$ \\
E & $20.2 \pm 0.6$ \\
F & $11.1 \pm 0.5$ \\
G & $12.2 \pm 0.3$ \\
\hline a The maximum level allowed by Brazilian legislation is $25 \%$.
\end{tabular}




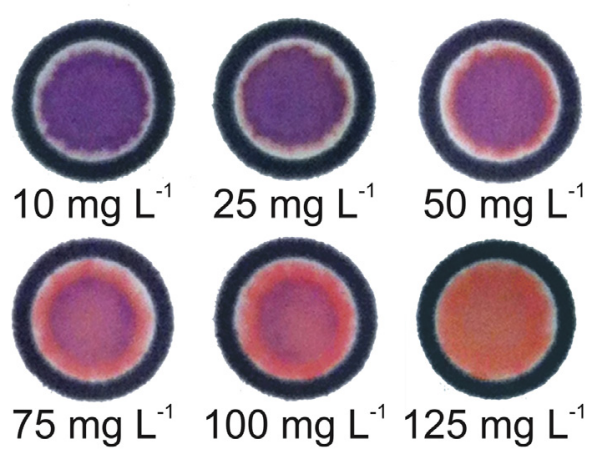

Fig. 5. Color palette for semi-quantitative visual determination of aluminum.

decreases of the analyte response, due to matrix effects. The possible existence of such effects was evaluated using recovery tests. The recovery values obtained for AHC were between $92.2 \%$ and $103.4 \%$, indicating an absence of interference from the compounds normally found in antiperspirants. Therefore, the sample matrix had no significant influence on the AHC determination [33]. Furthermore, aluminum is the only metal present at high concentrations in these types of formulations. Consequently, if the matrix happened to be contaminated with other metals that could bind to Alizarin S, the aluminum concentration would be much higher, hence minimizing any possible interference.

\section{Conclusions}

A new method was developed for the determination of aluminum hydrochloride in antiperspirant samples. The methodology was successfully validated and applied in the analysis of commercial samples. The paper platform employed is environmentally friendly, because it requires minimal volumes of reagent and sample, in contrast to spectrophotometric methods. No organic solvent is used, unlike chromatographic analytical techniques, and sample clean-up is fast and simple. The paper platform is from a renewable source and is readily available, inexpensive, and can be safely disposed of by incineration. In summary, the method is simple, portable, fast, low-cost, eco-friendly, and precise.

\section{Acknowledgements}

The authors are grateful for the financial support provided by the São Paulo State Research Foundation (FAPESP, grant \# 2015/21733-1), and the Brazilian National Council for Technological and Scientific Development (CNPq, grant \# 137253/2015-0).

\section{References}

[1] K. Laden, Antiperspirant and Deodorants, 2nd ed. Marcel Dekker, New York, 1999.

[2] G.E. Piérard, P. Elsner, R. Marks, P. Masson, M. Paye, EEMCO guidance for the efficacy assessment of antiperspirants and deodorants, Skin Pharmacol. Appl. Ski. Physiol. 16 (2003) 324-342.

[3] A. Benohanian, Antiperspirants and deodorants, Clin. Dermatol. 19 (2001) 398-405.

[4] D. Krewski, R.A. Yokel, E. Nieboer, D. Borchelt, J. Cohen, J. Harry, S. Kacew, J. Lindsay, A.M. Mahfouz, V. Rondeau, Human health risk assessment for aluminium, Aluminium oxide, and aluminium hydroxide, J. Toxicol. Environ. Health, Part B 10 (2007) $1-269$.
[5] N. Ouadah, C. Moire, J.-F. Kuntz, F. Brothier, H. Cottet, Analysis and characterization of aluminum chlorohydrate oligocations by capillary electrophoresis, J. Chromatogr. A 1492 (2017) 144-150.

[6] L. Elečková, M. Alexovič, J. Kuchár, I.S. Balogh, V. Andruch, Visual detection and sequential injection determination of aluminium using a cinnamoyl derivative, Talanta 133 (2015) 27-33.

[7] Z.D. Draelos, Dermatologia Cosmética, 1st ed., 2012 Santos.

[8] D.L. Teagarden, J.O.E.L. White, S.L. Hem, Aluminum chlorohydrate III: conversion to aluminum hydroxide, J. Pharm. Sci. 70 (1981) 808-810.

[9] A.C. Alfrey, Aluminum toxicity in patients with chronic renal failure, Ther. Drug Monit. 15 (1993) 593-597.

[10] V. Kumar, K.D. Gill, Aluminium neurotoxicity: neurobehavioural and oxidative aspects, Arch. Toxicol. 83 (2009) 965-978.

[11] O. Egbuna, A. Bose, Acute aluminum neurotoxicity secondary to treatment of severe hyperphosphatemia of acute renal failure and the K/DOQI guidelines: a case report and review of the literature, Internet J. Nephrol. 2 (2004) 2-7.

[12] M.L. Hegde, P. Shanmugavelu, B. Vengamma, T.S.S. Rao, R.B. Menon, R.V. Rao, K.S.J. Rao, Serum trace element levels and the complexity of inter-element relations in patients with Parkinson's disease, J. Trace Elem. Med. Biol. 18 (2004) 163-171.

[13] L.N. Prista, M.F.G. Bahia, E. Vilar, Desodorizantes e antiperspirantes, in: Dermofarmacia e Cosmética, Associação Nacional de Farmácias, Porto, 1995 425-473.

[14] ANVISA-Agência Nacional de VigilânciaSanitária, Resolução RDC no 79, de 28 de agosto de 2000, Brasília, 2000.

[15] P.D. Darbre, F. Mannello, C. Exley, Aluminium and breast cancer: sources of exposure, tissue measurements and mechanisms of toxicological actions on breast biology, J. Inorg. Biochem. 128 (2013) 257-261.

[16] P.J. Hardefeldt, S. Edirimanne, G.D. Eslick, Deodorant use and breast cancer risk, Epidemiology 24 (2013) 172

[17] R.M. Rodrigues-Peres, S. Cadore, S. Febraio, J.K. Heinrich, K.P. Serra, S.F.M. Derchain, J. Vassallo, L.O. Sarian, Aluminum concentrations in central and peripheral areas of malignant breast lesions do not differ from those in normal breast tissues, BMC Cancer 13 (2013) 104-111.

[18] E. Kalogria, A. Varvaresou, S. Papageorgiou, E. Protopapa, I. Tsaknis, A. Matikas, I. Panderi, Pre-column derivatization HPLC procedure for the quantitation of aluminium chlorohydrate in antiperspirant creams using quercetin as chromogenic reagent, Chromatographia 77 (2014) 1275-1281.

[19] A. López-Gonzálvez, M.A. Ruiz, C. Barbas, Validated flow-injection method for rapid aluminium determination in anti-perspirants, J. Pharm. Biomed. Anal. 48 (2008) 340-346.

[20] L.S. Kasim, B. O., O. D.J., J. O.O., A. Olatunde, Quantitative assessment of metals in some antiperspirant formula marketed in nigeria, J. Pharm. Sci. Innov. 2 (2013) 1-4.

[21] L. Byrne, J. Barker, G. Pennarun-Thomas, D. Diamond, S. Edwards, Digital imaging as a detector for generic analytical measurements, Trends Anal. Chem. 19 (2000) 517-522.

[22] V.H.M. Luiz, L. Pezza, H.R. Pezza, Determination of nitrite in meat products and water using dapsone with combined spot test/diffuse reflectance on filter paper, Food Chem. 134 (2012) 2546-2551.

[23] V.H.M. Luiz, L. Pezza, H.R. Pezza, Rapid determination of furosemide by combined spot test/diffuse reflectance spectroscopy to detect doping in sport, Microchem. J. 109 (2013) 68-72.

[24] E. Carrilho, A.W. Martinez, G.M. Whitesides, Understanding wax printing: a simple micropatterning process for paper-based microfluidics, Anal. Chem. 81 (2009) 7091-7095.

[25] J. Adkins, K. Boehle, C. Henry, Electrochemical paper-based microfluidic devices, Electrophoresis 36 (2015) 1811-1824

[26] W. Dungchai, O. Chailapakul, C.S. Henry, Use of multiple colorimetric indicators for paper-based microfluidic devices, Anal. Chim. Acta 674 (2010) 227-233.

[27] W. Liu, Y. Guo, H. Li, M. Zhao, Z. Lai, B. Li, A paper-based chemiluminescence device for the determination of ofloxacin, Spectrochim. Acta A Mol. Biomol. Spectrosc. 137 (2015) 1298-1303.

[28] M.I. Milani, E.L. Rossini, K. Castoldi, L. Pezza, H.R. Pezza, Paper platform for reflectometric determination of furfural and hydroxymethylfurfural in sugarcane liquor, Microchem. J. 133 (2017) 286-292.

[29] F. Feigl, Spot Test in Inorganic Analysis, 6th ed. Elsevier Science, New York, 1982.

[30] M. Chamsaz, M.H. Arbab Zavar, M.S. Hosseini, Flotation spectrophotometric determination of aluminium with alizarin, Anal. Lett. 33 (2000) 1625-1633.

[31] R.S. Sathish, M.R. Kumar, G.N. Rao, K.A. Kumar, C. Janardhana, A water-soluble fluorescent fluoride ion probe based on Alizarin Red S - Al (III) complex, Spectrochim. Acta A 66 (2007) 457-461.

[32] M. Thompson, S.L.R. Ellison, R. Wood, Harmonized guidelines for single-laboratory validation of methods of analysis, Pure Appl. Chem. 74 (2002) 835-855.

[33] L. Huber, Validation of analytical methods: review and strategy, LC/GC Mag. 21 (1999) 1-17. 